\title{
Chapter 23 \\ Educational Methods Using \\ Intergenerational Interaction to Fight \\ Ageism
}

\author{
María del Carmen Requena, Hannah J. Swift, Laura Naegele, \\ Marc Zwamborn, Susan Metz, Wilco P. H. Bosems, and Joost van Hoof
}

\subsection{Introduction}

The social phenomenon of ageing has deeply modified contemporary societies, making it possible that three or more generations live together within the same chronological environment. Even though this development can be viewed as a great achievement, it does not mean that societies have changed their often negative concept of older generations. This holds particularly true for younger generations, as they, for example, often view older persons as conservative, petulant and pessimistic (Requena and Gonzalez 2008). Studies that explain ageist behaviour tend to focus on the micro level (linking ageist attitudes with individual characteristics) or on the macro level, where ageist behaviour is attributed to shared cultural norms and attitudes that shape individual, organisational and societal behaviour regarding certain age cohorts (Shiu et al. 2015). As multigenerational societies become the norm,

M. del Carmen Requena ( $\triangle)$

Department of Psychology, Universidad de León, León, Spain

e-mail: c.requena@unileon.es

H. J. Swift

Centre for the Study of Group Processes, School of Psychology, Keynes College, University

of Kent, Canterbury, UK

e-mail: H.J.Swift@kent.ac.uk

L. Naegele

Institute of Gerontology (IfG), University of Vechta, Vechta, Germany

M. Zwamborn · S. Metz

Summa College, Summa Healthcare, Eindhoven, The Netherlands

W. P. H. Bosems · J. van Hoof

Centre for Healthcare and Technology, Fontys University of Applied Sciences,

Eindhoven, The Netherlands

L. Ayalon, C. Tesch-Römer (eds.), Contemporary Perspectives on Ageism,

International Perspectives on Aging 19,

https://doi.org/10.1007/978-3-319-73820-8_23 
rather than the exception in Europe, the question of how existing prejudices and age cohort related discrimination could be tackled arises.

Within this context education plays an important role. The sector of higher education, in particular, aims to form professionals in this new multigenerational landscape and it must be aware of its double role as a tool to combat demeaning stereotypes based on ageing and prevent ageist beliefs and attitudes. Ideally, higher education incorporates learning social competences and interpersonal abilities, and this perspective faces implicit stereotypes because it removes social conventionalisms and shared expectancies where ageist stereotypes are grounded.

Theoretical frames based on intergroup theories (Stephan and Mealy 2011) lay out how coexistence and participation in a common space favours personal knowledge and avoids explicit ageism (Hagestad and Uhlenberg 2005). Intergroup theories propose that positive intergenerational relations, which require personal involvement beyond the mere coexistence, can reduce implicit ageist attitudes and values. Intergenerational relations presuppose a double bond between persons: one is affective and another one is based on specific interaction rules within the community. Research has shown that affective bonds promoted by personal relationships are significantly related to the lack of implicit ageist stereotypes (Jost et al. 2004). This kind of intergenerational relations is present in family or labour contexts, but is underrepresented in formal educative environments, which are typically homogeneous regarding age. It is not usual to find older persons sharing the classroom with younger students, unless when intentionally prepared. It is also not usual to find young and older persons sharing leisure places unless some kind of emotional bond is present. Therefore, higher education institutions have the responsibility to promote educative intergenerational experiences both within the formal academic environment and beyond it in real life contexts. Students find the chance to put into practice not only the technical knowledges acquired in their studies, but develop affective bonds and prosocial abilities by means of intergenerational encounters.

A myriad of concrete examples illustrate these ideas. Consider how young European nursing students prefer not to work in the ageing sector, even if it is a major source of employment. For example, studies on the professional preferences among students of degrees such as medicine, social work or education show that they begin their studies preferring to work with children or young persons, while the practice with older persons is generally neglected to the last ordinal preference (Kalisch et al. 2013). This lack of interest is not only related to the emergence of negative memories and experiences but also to erroneous beliefs and myths about age and ageing (Requena and Gonzalez 2008). Such tenets are based on outdated socio-cultural patterns of interaction between generations especially among young persons and first year university students. In contrast, it has been confirmed that intergenerational groups linked by commercial or ephemeral bonds are less efficient in terms of prosocial interaction than affectively loaded intergenerational relations (Chonody and Wang 2014).

This chapter presents theoretical models, methodologies and a case-study, which exemplify and lay the foundation for an applied educative model based on the combination of scientific knowledge delivered in classrooms with experiential 
methodologies. In particular, the proposed approach combines technical instruction with person-centred education as a successful formula to fight implicit ageist stereotypes in higher education. The chapter starts out with outlining three theoretical frameworks (Intergroup Contact Theory, Intergenerational Contact Theory and the Concept of Generational Intelligence) and aims to explain in educational contexts how intergenerational contact can help to prevent discrimination based on age. Subsequently the illustration of concrete experiential methodologies in higher education that facilitate intergenerational contact are outlined, the chapter ends with the presentation of the case study "Senior in Class", conducted in the Netherlands, that can be considered as a 'good practice' example of intergenerational contact intervention to preventing ageism.

\subsection{Theoretical Frames}

\subsubsection{Intergroup Contact Theory}

Intergroup contact theory (Allport 1954) is a social psychological theory, which suggests that, under the right conditions, contact or interactions between members of opposing groups may improve attitudes and bring about a reduction in intergroup prejudice and stereotypes. The optimal conditions specified by Allport include equal status between group members, working towards a common aim or goal, providing an opportunity for intergroup cooperation and institutional support or support from an authority figure. Research has identified further conditions that facilitate the beneficial effects of intergroup contact. For instance, Cook (1962) highlighted the importance of intimacy within the interaction and suggests this underpins the potential to see the interaction partner as more than an 'acquaintance', which is likely to facilitate the development of a cross-group friendships (i.e., friendships between people who belong to different social groups). Indeed, cross-group friendships are a direct form of intergroup contact. Pettigrew's (1998) review found that individuals with friends from different social groups had significantly lower levels of in-group bias, and it is the most likely type of contact to result in positive outcomes, including, a reduction of prejudice and increase in sympathy towards, and admiration of, outgroup members (Pettigrew 1997; Davies et al. 2011).

Since Allport introduced intergroup contact theory as a means of prejudice reduction, there have been many studies exploring its effects, in various contexts, with a range of outgroup targets (predominately race and ethnicity, followed my mental or physical disability and sexual orientation). In 2006, Pettigrew and Tropp conducted an extensive review and meta-analysis of 515 of these studies, conducted between 1940 and 2000, that included more than 250,000 participants. The results showed that studies adhering to Allport's optimal conditions of contact tend to produce larger effects and are therefore, generally seen as more successful in reducing prejudice. However, studies that didn't adhere to these conditions tend to produce smaller effects, but were also considered successful at reducing prejudice. Therefore, the 
authors concluded that these conditions should be seen as facilitating factors, rather than essential conditions for prejudice reduction. In addition, research has shown that the prejudice reduction effects of intergroup contact are generalizable beyond the original contact partner (Pettigrew and Tropp 2006). In other words, contact interactions between people who belong to different social groups can reduce prejudice towards the contact partner's entire outgroup (as well as to the contact partner), resulting in changes in attitudes towards groups of people. The findings of the metaanalysis, in which $10 \%$ of the studies explored contact interactions between different age groups, has significant implications for intergenerational contact (i.e., contact between members of different age groups or generations), suggesting that it is viable prejudice reduction technique capable of reducing ageist attitudes towards contact partners, as well as prejudice towards older adults in general.

\subsubsection{Intergenerational Contact Theory}

The majority of intergenerational contact research tends to focus on the effects of intergenerational interactions that take place during day-to-day life, and reveals that positive intergroup contact is related to more positive outcomes, including a decrease in explicit and implicit negative attitudes towards older adults (see Drury et al. in press for review) and tend to lead to more positive behavioural intentions, such as intentions to donate to charities that support older people, and agreeing to spend more time with older adults (Bousfield and Hutchison 2010; Hutchison et al. 2010). This is particularly the case when young people's experiences were frequent and of good quality, in other words, considered to be positive interactions (Hutchison et al. 2010).

However, just like intergroup contact, there are different types of intergenerational contact, which can occur in a range of settings. For instance, cross-group friendships are a direct form of contact, but contact can also be indirect, such as extended contact and imagined contact. Extended contact works on the basis that a-friend-of-yours-is-a-friend-of-mine (Wright et al. 1997). For example, the knowledge that a same aged friend has a friend, who is an older adult, can reduce ageism. Imagined contact works simply by asking people to imagine having a positive encounter or interaction with someone (usually asked to imagine a stranger) from another social group. For example, in two studies, undergraduate students who imagined a positive interaction with an older adult stranger reported less prejudice and bias toward older adults compared to students, who imagined an outdoor scene (Turner et al. 2007). However, unfortunately it seems that opportunities for meaningful interactions between generations and opportunities to from cross-generational friendships between generations are rare. Evidence from the European Social Survey shows that $80 \%$ of respondents aged $15-24$ have no friends aged 70 and over (Abrams et al. 2011). There are often significant barriers and obstacles to the formation of cross-group friendships, particularly between people from different 
age groups. Therefore, intergenerational contact programmes, are often used to fill this void and provide opportunities to bring generations together with the aim of improving intergenerational relationships.

\subsubsection{Generational Intelligence}

The emerging model called "generational intelligence" offers a conceptual frame to interpret the complex and multidimensional issue of intergenerational relations. Against the backdrop of constantly shifting socio-demographics, the model takes the dual challenges of being placed in the situation of another generation, while simultaneously negotiating sustainable relationships amongst members of different generations (Biggs et al. 2011). Generational intelligence is defined as the capacity to reflect and act towards the comprehension of oneself and others as members of an age group, of a cohort, and of a family living in a present social and cultural context. Young and old coordinate common chronological time with roles, which can differ between generations. For example, in the past, the older persons were the holders of wisdom while currently young persons have a better access to knowledge. In the past, the social role determined by the pair education-work was significantly less dependent on chronological age. For example, work was distributed in terms of family needs, not in chronological terms when children had to leave school to work and help at home. Moreover, in contemporary societies there are manifold temporal contexts occupied by several generations sharing the same chronological time. An essential feature of generational intelligence is using education to encourage people to understand the temporal context of others. This model does not search for a neutral age and does not presuppose that age is irrelevant. Rather, the model focuses on creating spaces where age is distinctive from several generational points of view, and suggests this must be taken into account within a pragmatic negotiation process. The social classification of people according to age influences the expectations of the roles played by citizens at different ages: children play, young people study, adults work and the elderly rest. However, the real plurality of significant roles played by older persons (such as support for the family, caring for their grandchildren and support for the community through volunteering) goes beyond the tripartite social structure education-work-pension. There are severe discursive limitations on the expectancies of older persons because their identity and responsibility are impoverished (Biggs and Lowenstein 2013).

The National Council on Aging of the U.S.A. (Ventura-Merkel and Lidoff 1983), for instance, proposes the development of generational intelligence through activities that increase cooperation, interaction or exchange between two generations. The exchange is more than the mere fact of bringing together young and old, since it aims at the organised achievement of benefits for both generations. The copresence of older and young people should promote generational know-how 
together with the ability to use it as a key and non-decorative element of generational interventions. Decisions about the content of these programmes are made taking into account as a priority objective the generational educational exchange that, precisely because they are different from each other, can create a space for communication, dialogue, encounter and learning (McClusky 1990).

The presented frameworks stress the potential of reducing existing age-related stereotypes through direct interaction between different generations. Establishing ties between different generations is essential in order for members of different age cohorts to discuss differences between them as well as to express their need for each other (Manheimer 1997). Such ties include interactions that happen through the exchange of knowledge, such as young people introducing older people to the use of technologies, while older people contribute their vital life and work experience to younger generations. The idea of intergenerational knowledge exchange is rather common in the social sphere of work, for example, as part of mixed-age groups in general. However, this chapter aims to look at the higher educational sector and its potential for reducing ageism through intergenerational contact. It should be mentioned that programmes, aimed at fostering this intergenerational contact, are not exempt of unexpected results that can end in failure and therefore, careful planning and constant supervision are required (Sánchez and Kaplan 2014). The following chapter (2018; Chap. 24) introduces the method of "Experiential Service-Learning" as a vehicle for facilitating interaction amongst different cohort members and provides the methodical background for the case study presented in the closing of this chapter.

\subsection{Experiential Service-Learning}

Educational practices in ageing societies are constantly exploring new inclusive educational methodologies for all ages. According to the theoretical models previously proposed, it is necessary to balance the current curriculum based on the acquisition of an extensive body of theoretical knowledge with new experiential learning methodologies that favour not exclusively academic formation, but also communitybased learning. John Dewey (1916-1995) is acknowledged as the creator of the theoretical rationale for contemporary academic Service-Learning: "Experience is better than a ton of theory because it is only in experience that any theory has vital and verifiable experience" This author argued for the advantages of offering significant experiences with which students can acquire knowledge and develop abilities to solve real world problems. Dewey's proposal is to incorporate concrete experiences into the learning process with an ulterior critical reflection on the experience (Conway et al. 2009). The success of Service-Learning as a powerful strategy able to improve learning and foster an engaged citizenship against ageism is well documented (Basran et al. 2012). In fact, research showed that students taking part in Service-Learning Programmes obtain better academic records, increase their 
self-efficacy, enrich their personal identity, their social conscience and self-confidence and are more aware of their civic and ethical responsibilities towards the sociocultural context where they live.

The Service-Learning planning methodology requisites, established by the National Service-Learning Clearinghouse (NSLC) (Gallagher 2007), are the following:

- The production of knowledge departs from problems rather than from disciplines;

- Problems faced by Service-Learning strategies and their solutions are handled with academic tools and scientific rigour. The activities should foster social links to articulate Service-Learning within and without the classroom;

- Active participation of students in all phases of the Service-Learning field work, including diagnostic, planning, management, results, evaluation and reflection (see the project "Seniors in Class" below);

- The evaluation of solidary attitudes amongst different generations has the same weight as academic learning;

- Reflection on results. To achieve this requirement it is appropriate to use evaluation tools such as discussion groups and portfolio, described in the case study in the following section.

\subsubsection{Service-Learning in Higher Education}

Within the context of higher education (universities and colleges) Service-Learning methodology begins with the American Compact Campus in the 1990s. This campus is currently shared by more than 959 colleges, universities, public and private educational institutions in more than 30 states throughout the United States of America. The mission of these centres is to promote civic responsibility through knowledge transmission and community-based research. Europe also was influenced by Service-Learning methods. Among the first initiatives stands out the 2003 created European Service-Learning Association and the EU project CIVICUS, promoted by the Vytautas Magnus University in Lithuania, in which forms of cooperation between universities and companies were explored (Natalija and Deivida 2011). The Netherlands Centre for Social Development (Movisie) is one of the main entities disseminating Service-Learning (Lub et al. 2009), including special attention to older persons. The drop of voluntary work in society forced the government to rule that all students must work between 48 and $72 \mathrm{~h}$ in Service-Learning activities from September 2010 onwards. Service-Learning was introduced in the curriculum in 2007 and obtained compulsory status in 2011. Similar centres are created in Sweden and Switzerland. ${ }^{1}$ In the United Kingdom, Service-Learning practices are understood as citizenship education and they are organized by civic extra-academic

\footnotetext{
${ }^{1}$ www.servicelearning.ch
} 
institutions such as Community Service Volunteers. For example, outstanding intergenerational programmes incorporate old persons as mentors of difficult school children (Jerome 2012). Germany founded the network Lernen durch Engagement, ${ }^{2}$ which includes excellence and cooperative centres and is active in the publication of materials. In Spain, the network Red Estatal de Aprendizaje-servicio and in Barcelona the Red ApS-U organise Service-Learning activities promoted by a group of older persons and retired professionals, like the iaioflautas. ${ }^{3}$

\subsubsection{Reasons for the Service Learning Model in University Settings}

The university as an institution must articulate educational programmes, lines of research and civic missions that together reflect the key elements of the curriculum of students as future professionals. In particular, service learning methodologies in higher education settings: (1) are not a panacea (or new magic recipe) but an educational approach consistent with the intention to achieve meaningful learning experiences and create genuine theory/praxis interfaces, (2) mobilises teaching resources for new realities. The rejection and avoidance of patterns of social discrimination and stereotyped behaviour such as ageism are realistic curricular objectives of experiential methodologies (Brown et al. 2013). The European Higher Education Area has reformulated the concept of higher education with the incorporation of ethical education including values and attitude education, However, no curricular space have been granted to these aspects. Therefore, these learnings are to be acquired by extracurricular activities and a transversal approach to the curriculum (see the example offered in the "Seniors in Class" project case study). The difference between practical curricular activities and service learning is the compulsory character of the former. Curricular activities are obligatory in order to obtain an academic title, while service learning experiences must be conceived in a less rigid way, not as a bureaucratic requirement but as an experiential methodology valued beyond the academia. The following section describes the project of the third age class, cross-curricular approach based on the service learning methodology.

\subsection{Seniors in Class Project: A Case Study}

This section describes the different phases of an ongoing service learning experience, which follows the National Service-Learning Clearinghouse methodology (Fig. 23.1). The project 'Seniors in Class" (Dutch: 'Senioren in de Klas DOEN!') is

\footnotetext{
${ }^{2}$ www.servicelearning.de

${ }^{3}$ http://www.iaioflautas.org
} 
Fig. 23.1 Phases of the service-learning field work

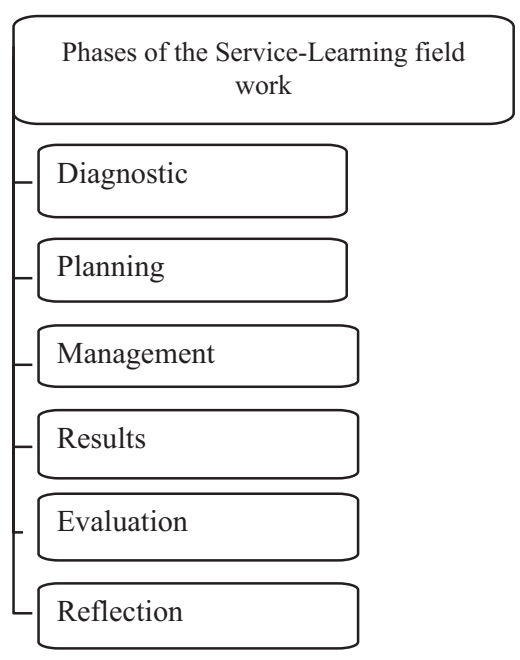

a project which concerns the improvement of the educational programme, involving the active participation of seniors in lectures and workshops, in this case, in the domain of healthcare and technology. This project is a joint project of Fontys University of Applied Sciences and Summa College in Eindhoven, The Netherlands (van Hoof et al. 2015b). Besides fostering the academic learning of the studentparticipants, this project also puts a focus on facilitating intergenerational contact and developing generational intelligence through inviting seniors to actively participate in class.

\subsubsection{Phases of the Service-Learning Field Work}

In the Netherlands, the provision of healthcare and welfare services for the older population is a topical subject in politics at national and local levels, and features heavily in the media. Older people are expected to age-in-place, thresholds for admission to long-term care facilities are growing ever higher, and existing nursing home capacity is being re-evaluated in terms of quantity and quality. Health care schemes that were once provided by the state are now being substituted by solutions and services at the local level, some of which include a wide array of healthcare and welfare technologies. The education programmes of universities of applied sciences and vocational colleges in the domains of healthcare and welfare are, therefore, continuously updated in terms of the inclusion of societal themes and new developments (van Hoof et al. 2015a). One of the projects which concerned the improvement of educational programmes involves the active participation of seniors in lectures and workshops, in this case, in the domain of healthcare and technology. 


\subsubsection{Planning}

The project aims to involve older adults (explicitly referred to as 'seniors' as requested by the participants of the project) with students in education related to the design and application of technology in healthcare in order to combat age stereotypes and ageism. In order to achieve this general objective, three goals were placed central in the project, which directly relate to some of the facilitating conditions for intergroup contact:

- First, the project wanted to present seniors as societal role models. A role model is not per se a successful businessman or a famous person. In this project, a role model is someone who is right in the middle of a certain societal problem or challenge, such as a senior who actively uses numerous means and solutions to keep functioning independently and maintain a social life. It is this group explicitly, that we wish to involve in our educational programme as 'old and gold', with a differentiation in terms of needs and interests for a certain type of educational method.

- Second, seniors work together during educational activities with students and lecturers (co-creation) in the field of design and evaluation of living environments and technologies. There is a mutual exchange of knowledge and skills, and design prototypes of students are being optimised.

- Third, by involving seniors in education, they indirectly receive didactical education and they participate more intensively in society. By giving attention in class to the topics that seniors are experts of, seniors have to prepare themselves in the context of a certain problem and the way the related knowledge can be transferred as optimally as possible. A lecturer has the task to support the senior in transferring this knowledge to the students.

In this project, the young participants were third and fourth year students of different educational programmes and a group of approximately 30 seniors between the age of 60 and 90 years old, who are no longer actively part of the work force. These seniors were willing to involve in the development and execution of new types of educational activities and methods in Summa College (educational programme of nursing and welfare) and Fontys University of Applied Sciences (educational programme of the minor healthcare and technology). The recruitment of the participants started out by contacting existing networks, such as organisations and associations for older people, and new networks to come into existence during the project itself. Some of the seniors knew of friends, acquaintances and other interested persons who joined the group of volunteers. Summa College had a large network of participating seniors who had an active engagement in the activities organised in the Lokaal+ initiative. Recruitment through a mailing to the association for retired workers of both educational organisations yielded more volunteers. The majority of participating seniors had higher education, had experience with educational methods, management, coaching of young persons and students, and presenting to groups. Only a few had a strong basis in the domain of healthcare and 


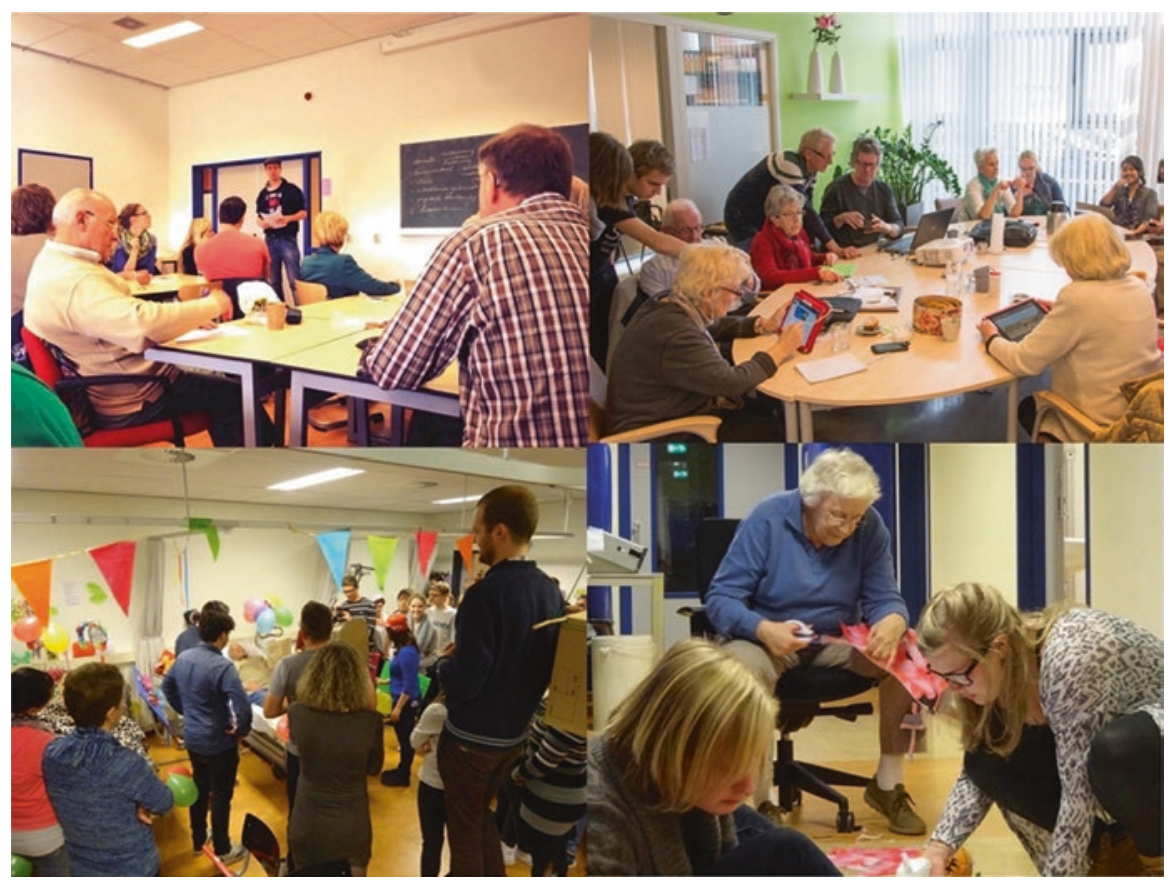

Fig. 23.2 Intergenerational cooperation during design classes, lectures and iPad instructions gatherings

technology. There were also some limitations that impacted the involvement of seniors, such as chronic back problems and impaired hearing.

\subsubsection{Management}

The project of the senior class was carried out at the Summa College and Fontys University of Applied Sciences worked together to arrange creative workshops for the project Nursing Home of the Future (van Hoof et al. 2014a, b, c, 2015c) and in the project Lokaal+ of Summa College. ${ }^{4}$ This project was financially supported by the Municipality of Eindhoven (Programma Leren in Eindhoven 2030).

In the first project, seniors were involved as active co-designers of technological solutions for bed-ridden residents of nursing homes (Fig. 23.2) (van Hoof et al. 2015c). Seniors, even those with mild dementia, can be excellent spokespersons for their own subgroup and contribute to design projects when receiving the right levels of support and instruction (Kort and van Hoof 2014). Together with students, seniors write scenarios for the interior design of nursing home rooms and improvements to

${ }^{4}$ http://www.summacollege.nl/over-summa-college/leuk-en-lekker/lokaal.html 
the direct surroundings of the bed itself, in order to support the self-care abilities of bed-ridden nursing home residents. In the second project, seniors learn how to use homecare technologies during training sessions by students from the nursing department. Lokaal+ is a meeting space, shaped as a small home, within the faculty building of Summa College, which is run by students who are supervised by lecturers. The Lokaal + initiative aims on community dwelling seniors, who live in the adjacent neighbourhoods, and who are welcome for a talk or activities, or to get a helping hand for small household tasks or societal support which is no longer provided for by the State of municipality. In a corner of the Lokaal+ facility, seniors can get acquainted in the VieDome Experience Centre with the possibilities of modern technologies (home automation systems) in the domain of smart homes and e-health. Students can provide assistance and instructions to seniors in the field of modern technologies, including the use of tablet computers and internet banking (Fig. 23.2), exploring the digital world which can pose problems in terms of accessibility and be ageist in its own way (Sourbati 2015). Both projects showed that the people involved (students, seniors and lecturers) gained insights from the interaction with each other, and that further research was needed as to how seniors could be involved in the educational programme in the most fitting and beneficial way.

\subsubsection{Procedure}

The seniors were informed that participating in the project provides a quality stimulus to the educational programmes. During their involvement, experiences and knowledge become available to the students. Through the project, seniors can exploit their value as life experts in an educational setting, and introduce students to the realm of aged care and implementation of technology to support the facilitation of care. Moreover, seniors serve as coaches and can share some of their life experiences. In the project, the participation of seniors means that they have again a tangible societal importance (as educators), have a chance to combat possible social isolation, gain new knowledge of technology and build a new social and semiprofessional network. The educational programmes, in turn, are being enriched by life experiences of seniors and expertise from outside of the universities and colleges. The involvement of seniors also provides opportunities to add a layer of depth in the curriculum, for instance, in relation to themes which require a certain degree of life experience, such as illness and pain, loss and mourning, euthanasia, and death. In addition, the seniors also made an appearance as simulation patients in practicing telecare (screen-to-screen e-health). With the students, the stereotyped image of a "grandmother or grandfather" was previously worked in front of the image of "old gold" that fine-tuned into a more subtle image that is a better presentation of a modern-day senior. The actual knowledge, skills and attitudes of the students become more realistic. This is an asset when making personas or fictional characters in design projects. 
The participation of seniors calls for creativity among the lecturers, as they have to come up with new ways to involve seniors in their educational programmes and methods. Seniors need to acquire a certain position in these lectures and workshops, in which their knowledge and skills can be exploited to the benefit of all. The large advantage of the involvement of seniors lies in the fact that students have direct access to the end-users of healthcare technology, whether these seniors are 'patients' using these technologies themselves, or as informal carers assisting a loved-one in need. The basis for the project is the creation of a win-win-situation.

Although the majority of seniors have skills to share with students, it does not automatically mean they wish to engage in the role of a lecturer and actively teach students. There was a general consensus in the project that the senior should not take over tasks from a lecturer and actually be a cheaper substitute for an existing lecturer on the pay roll of the school.

\subsubsection{Evaluation Tool}

The activities will be carried out through two cooperative methodologies: discussion groups and portfolio to be complicated as part of the evaluation, both during the process and at the end of it. The training sessions were conducted through the discussion group led by the project promoters in which the members of the project participated: seniors, students and teachers. As mentioned earlier, the discussion group not only provides information on the contents of an activity but also provides a space for interpersonal knowledge and offers opportunities to overcome emotional upheavals caused by erroneous beliefs about age stereotypes (Ferguson et al. 2013). In addition, the mutual support provided by the group improves the performance of activities (Wilson 1992). The portfolio is a collection of evidence that is considered pertinent, relevant and useful for the project: documents, cartoons, articles, publicity, stories, anecdotes, sound files and photographs. The portfolio is coordinated by the project leaders and built by the seniors, students and lectures participating in the project. The final part of the portfolio is a final reflection of the strengths, weaknesses and possible improvements.

\subsubsection{Results}

The majority of seniors said the instructions to participate in the project were clear and they indicated that they knew what was expected from them as a contribution to the achievement of the educational goals. Without any exception, seniors felt that they were treated with respect and that they had sufficient space and freedom for their own opinions and ideas. The participation turned out to be meaningful to the 
seniors, partly because of the valuable ideas they heard during discussions with students. Seniors stated that they learnt practical new things by participating in classes, such as getting acquainted with new technologies (tablet computers, e-health systems).

It became evident that seniors liked the fact that students were willing to share their own life experiences concerning illnesses and losses in open-hearted group discussions. During the sessions, seniors broke the ice and students soon followed. Because of the interaction a mutual understanding is developed, and insights are provided into each other's lives. The seniors and students learn to tune their communication skills to one another. This is another asset for students who pursue a career in the healthcare and welfare sectors. Seniors expressed a unanimous sense of joy from participating in the activities, and words as "collaboration", "listening", "mutual learning" were mentioned. Students were described by the seniors as "sincerely interested and involved."

Lectures and students valued the participation of seniors in the health and technology education programme as a "valuable contribution" because they acted as sounding board for the student, $\mathrm{t}$ as an experts who can help the student to sharpen ideas or to improve a design. In the words of one of the students, who was involved in the design of an interactive closet for dressing challenges in dementia:

\section{Brainstorming about our project together with seniors certainly gave use new insights. The seniors told us that it is important for care recipients to receive visual feedback. We started working on this feedback the same week. We have made $3 \mathrm{~d}$ prints of the handles in the shape of clothes. (student participate in the project)}

Finally, the participation of seniors in the project made it easier for them to see the friendly side of technologies. This fact contributes to alleviate the digital divide between generations that is behind some of the ageist beliefs.

\subsubsection{Evaluation}

The evaluation conducted through the discussion groups revealed the need to consider sociodemographic variability in future projects, in order to reflect the heterogeneity among seniors in Dutch society. Note that the group of major participants in this project belong to a group with a good educational level and a certain management of technologies. Considering the different typologies of seniors will not only have a greater efficiency in the resolution of technological projects, but also a greater respect and less ageist attitudes on the part of the majors, teachers and students. From a more content-based perspective, seniors valued working together with young people, for instance, having fruitful discussions with one another. Some of the reflections of the students make it clear: 
It was great fun to engage with actual seniors.

I though the lecture was nice and interesting, much nicer than the standard lectures because you can put theory into practice. I would like to have many more of such lessons.

I believe that these conversations and interactions make a deep impression on all students, and therefore stick to the collective mind. In addition, the seniors give us new insights because they were raised in a different time and also because they have more life experience. In short, I like to see more of it!

Finally, based on the information obtained in the discussion groups and portfolio, a large number of manuals were made for the interactive educational methods that are used for embedding the activities in the existing curricula. By doing so, the results become embedded in the routines of the educational programmes instead of an occasional activity. Currently, these manuals are being implemented in educational activities of other degrees such as the orthopaedic technology and applied gerontology classes.

\subsubsection{Reflection}

For future generational projects, prior training in intergenerational communication skills should be considered. One of the critical points identified in both discussion groups and in the portfolio were the difficulties in managing emotions and communication between participants. Regarding the turn of the word among the seniors, it was more complicated to solve because some seniors take on a more dominant role than others and this caused some irritation between them. On the other hand, the conversation between the students and seniors was overprotective or secondary talk of the baby, reflecting stereotypes attributed to seniors. Often, stereotyped behaviours are generally unconscious and accommodate the stereotype that is formed over the group with which it has to interact.

\subsection{Limitations of Educational Methodologies on Ageism}

There is still much to learn in higher education about potentially successful methodologies against ageism. Educational techniques such as experiential learning methodologies such as Service-Learning at a local, regional or international levels, concentrate in answering the how and the what for questions but lack a ripe theoretical body of knowledge sustaining them. Moreover, in this kind of educational experience several distinct institutions and entities are obliged to cooperate and share objectives, organisation and deployment of spaces, schedules, budgets and resources. Despite scattered academic university efforts to implement those programmes, such ventures often lack rigor or an ability to systematically measure their educational 
outcomes. Furthermore, professional education programmes in the scientific fields that may hold many of the solutions such as engineering, natural, social and health sciences find that their curricular schedules are too intensive to allow students to combine technical learning with programmes that serve the community. However, advanced societies require academic curricula that incorporate educative programmes contributing to generational and cultural coexistence in an increasingly aged and mobile world.

Faculty and institutions often find difficulties when it comes to the application of learning methodologies in the classroom. Students usually find that these methodologies require from them an additional work charge in their course. Sometimes they have problems with their own classmates and other team members, or consider they receive little help from their tutors. Also lecturers signal some difficulties regarding the amount of time they need to set up and manage their teaching out of classrooms. It is important to bear in mind that lecturers normally do not receive any support in the heavy administrative and organisational tasks derived from launching this type of programmes (Blakey et al. 2015). The institutions and entities fostering learning initiatives in the academic realm also face problems regarding the technical and personal inexperience of students in professional environments. Therefore, the new methodological initiatives require time investment in the adequate formation and supervision of students. Despite all these difficulties, methodologies such as story-telling and Service-Learning local, regional and international are steadily growing in all educative fields and the success in their application in general compensates the difficulties encountered (Blakey et al. 2015).

Regarding research designs and characteristics, experiential methodologies usually present specific limitations due to their educational origin. For example, studies are usually transversal and based on qualitative inquiries, diary data from students and self-evaluations. Samples are small and often not aleatory, comparison groups are not always present and participants are often self-selected. Answers are standardly recorded in the presence of the concerned professionals, and therefore student's answers can be systematically biased.

Not all experiential methodologies are successful, because some experiences may reinforce stereotypes or reflect a charitable conception of volunteering (doing for instead of doing with) (Egger 2008). Educating the next generation of professionals requires broad perspectives in the areas of social responsibility and global citizenship. Additionally, experiential methodologies rely on praxis-oriented theories which try to improve the participation and responsibility of students with respect to social life and global citizenship. Interdisciplinary methodologies out of the classrooms require from the docents high amounts of motivation and engagement. Experiential methodologies need not only an adequate academic niche, but also the support from financial and political decisions, in order to favour educational models based on generational intelligence and sensibility towards age idiosyncrasies. 


\subsection{Proposal for the Future}

Ageing brings unknown sceneries in which several generations and life styles meet during prolonged periods. We need to promote a theoretical model as "having an open mind while actively seeking to understand generational norms and expectations of others, and leveraging this gained knowledge to interact, communicate and work effectively in diverse environments" (Hunter et al. 2004).

The interconnected and accessible flat world in which we live gives us the chance to appreciate how all human cultures share a common interest in fostering inclusive societies for all ages. In order to develop generational intelligence, it is necessary to educate specific knowledge, skills, and attitudes, including maintaining openness to other generations and other cultures, withholding judgment, respecting and valuing differences and tolerating ambiguity (Songer and Breitkreuz 2014). Learners build on these attitudes by gaining knowledge of cultures, customs, beliefs, and by becoming generationally self-aware (Deardorff 2006). People with generational intelligence are able to observe, evaluate, analyse, interpret, and, finally, relate to others in variable generational and cultural keys (Deardorff 2006; Breitkreuz and Songer 2015).

Author Contributions $\mathrm{M}^{\mathrm{a}}$ del Carmen and J. van Hoof jointly planned and conceived the chapter. J. van Hoof, M. Zwamborn, S. Metz, W.P.H. Bosems contributed to the chapter through their case study of the Seniors in Class project. Hannah Swift wrote the theoretical frame and Laura Naegele brought together the different sections of the chapter.

\section{References}

Abrams, D., Russell, P. S., Vauclair, M., \& Swift, H. (2011). Ageism in Europe: Findings from the European social survey. London: Age UK.

Allport, G. W. (1954). The nature of prejudice. Cambridge, MA: Perseus Books.

Ayalon, L., \& Tesch-Römer, C. (2018). Researching ageism. In L. Ayalon \& C. Tesch-Römer (Eds.), Contemporary perspectives on ageism: Vol. 19. International perspectives on aging (pp. 403-406). Berlin: Springer.

Basran, J. F., Dal Bello-Haas, V., Walker, D., MacLeod, P., Allen, B., D’Eon, M., et al. (2012). The longitudinal elderly person shadowing program: Outcomes from an interprofessional senior partner mentoring program. Gerontology \& Geriatrics Education, 33(3), 302-323.

Biggs, S., \& Lowenstein, A. (2013). Generational intelligence: A critical approach to age relations. New York: Routledge.

Biggs, S., Haapala, I., \& Lowenstein, A. (2011). Exploring generational intelligence as a model for examining the process of intergenerational relationships. Ageing and Society, 31(7), $1107-1124$.

Blakey, J. M., Theriot, S., Cazzell, M., \& Sattler, M. (2015). Is service-learning worth it?: A mixedmethods study of faculty's service-learning experiences. The International Journal of Research on Service-Learning and Community Engagement, 3(1), 18 pages.

Bousfield, C., \& Hutchison, P. (2010). Contact, anxiety, and young people's attitudes and behavioral intentions towards the elderly. Educational Gerontology, 36, 451-466. https://doi. org/10.1080/03601270903324362 
Breitkreuz, K. R., \& Songer, T. D. (2015). The emerging 360 degree model for global citizenship education. The International Journal of Research on Service-Learning and Community Engagement, 3(1).

Brown, G. A., Bull, J., \& Pendlebury, M. (2013). Assessing student learning in higher education. New York: Routledge.

Chonody, J. M., \& Wang, D. (2014). Predicting social work students' interest in gerontology: Results from an international sample. Journal of Gerontological Social Work, 57(8), 773-789.

Conway, J. M., Amel, E. L., \& Gerwien, D. P. (2009). Teaching and learning in the social context: A meta-analysis of service learning's effects on academic, personal, social, and citizenship outcomes. Teaching of Psychology, 36(4), 233-245.

Cook, S. W. (1962). The systematic analysis of socially significant events. Journal of Social Issues, $18,66-84$.

Davies, K., Tropp, L. R., Aron, A., Pettigrew, T. F., \& Wright, S. C. (2011). Cross-group friendships and intergroup attitudes: A meta-analytic review. Personality and Social Psychology Review, 15(4), 332-351.

Deardorff, D. K. (2006). Identification and assessment of intercultural competence as a student outcome of internationalization. Journal of Studies in International Education, 10(3), 241-266.

Drury, L., Abrams, D., \& Swift, H. J. (in press). Making intergenerational connections: An evidence review. London: Age UK.

Egger, J. B. (2008). No service to learning: "Service-learning" reappraised. Academic Questions, 21(2), 183-194.

Ferguson, S. M., Phillips, P. E., Roth, B. L., Wess, J., \& Neumaier, J. F. (2013). Direct-pathway striatal neurons regulate the retention of decision-making strategies. Journal of Neuroscience, 33(28), 11668-11676.

Gallagher, S. H. (2007). A qualitative research study of service learning in three undergraduate business courses. Lowell: University of Massachusetts.

Hagestad, G. O., \& Uhlenberg, P. (2005). The social separation of old and young: A root of ageism. Journal of Social Issues, 61(2), 343-360.

Hutchison, P., Fox, E., Laas, A., Matharu, J., \& Urzi, S. (2010). Anxiety, outcome expectancies, and young people's willingness to engage in contact with the elderly. Educational Gerontology, 36, 1008-1021. https://doi.org/10.1080/03601271003723586

Hunter, L. M., Hatch, A., \& Johnson, A. (2004). Cross-national gender variation in environmental behaviors. Social Science Quarterly, 85(3), 677-694.

Jerome, L. (2012). Service learning and active citizenship education in England. Education, Citizenship and Social Justice, 7(1), 59-70.

Jost, J. T., Banaji, M. R., \& Nosek, B. A. (2004). A decade of system justification theory: Accumulated evidence of conscious and unconscious bolstering of the status quo. Political Psychology, 25(6), 881-919.

Kalisch, H. R., Coughlin, D. R., Ballard, S. M., \& Lamson, A. (2013). Old age is a part of living: Student reflections on intergenerational service-learning. Gerontology \& Geriatrics Education, 34(1), 99-113.

Kort, H. S. M., \& van Hoof, J. (2014). Design of a website for home modifications for older persons with dementia. Technology and Disability, 26(1), 1-10.

Lub, V., Van Arum, S., \& Sprinkhuizen, A. (2009). Voor het verval. Belemmeringen en voorwaarden voor vroegsignalering en bewonersparticipatie. Journal of Social Intervention: Theory and Practice, 18(4), 62-82. (in Dutch).

Manheimer, R. J. (1997). Generations learning together. Journal of Gerontological Social Work, 28(1-2), 79-91.

McClusky, H. Y. (1990). The community of generations: A goal and a context for the education of persons in the later years. InIntroduction to educational gerontology (pp. 59-83). Washington, DC: Hemisphere. 
Natalija, M., \& Deivida, V. (2011). Service-learning in Lithuania: Escape from narrow professionalism. Образование через всю жизнь: непрерывное образование в интересах устойчивого развития, (9), 141-144 (in Russian).

Pettigrew, T. F. (1997). Generalized intergroup contact effects on prejudice. Personality and Social Psychology Bulletin, 23, 173-185.

Pettigrew, T. F. (1998). Intergroup contact theory. Annual Review of Psychology, 49(1), 65-85.

Pettigrew, T. F., \& Tropp, L. R. (2006). A meta-analytic test of intergroup contact theory. Journal of Personality and Social Psychology, 90(5), 751-783.

Requena, C., \& Gonzalez, M. (2008). Effects of intergenerational interaction on aging. Educational Gerontology, 34(4), 292-305. https://doi.org/10.1080/03601270701883908

Sánchez, M., \& Kaplan, M. (2014). Intergenerational learning in higher education: Making the case for multigenerational classrooms. Educational Gerontology, 40(7), 473-485.

Shiu, E., Hassan, L. M., \& Parry, S. (2015). The moderating effects of national age stereotyping on the relationships between job satisfaction and its determinants: A study of older workers across 26 countries. British Journal of Management, 26(2), S. 255-S. 272. https://doi. org/10.1111/1467-8551.12091

Songer, A. D., \& Breitkreuz, K. R. (2014). Interdisciplinary, collaborative international service learning: Developing engineering students as global citizens. International Journal for Service Learning in Engineering, Humanitarian Engineering and Social Entrepreneurship, 9(2), $157-170$.

Sourbati, M. (2015). Age(ism) in digital information provision: The case of online public services for older adults. InInternational conference on human aspects of IT for the aged population (pp. 376-386). New York: Springer.

Stephan, W. G., \& Mealy, M. D. (2011). Intergroup threat theory. InThe encyclopedia of peace psychology. Hoboken: Wiley.

Turner, R. N., Crisp, R. J., \& Lambert, E. (2007). Imagining intergroup contact can improve intergroup attitudes. Group Processes \& Intergroup Relations, 10, 427-441. https://doi. org/10.1177/1368430207081533

van Hoof, J., Dooremalen, A. M. C., Wetzels, M. H., Weffers, H. T. G., \& Wouters, E. J. M. (2014a). Exploring technological and architectural solutions for nursing home residents, care professionals and technical staff: Focus groups with professional stakeholders. International Journal for Innovative Research in Science and Technology, 1(3), 90-105.

van Hoof, J., Wetzels, M. H., Dooremalen, A. M. C., Nieboer, M. E., van Gorkom, P., Eyck, A. M. E., Zwerts-Verhelst, E. L. M., Peek, S. T. M., van der Voort, C. S., Moonen, M. J., van Dijck-Heinen, C. J. M. L., Weffers, H. T. G., Overdiep, R. A., Aarts, S., Vissers-Luijcks, C., \& Wouters, E. J. M. (2014b). The essential elements for a nursing home according to stakeholders from healthcare and technology: Perspectives from multiple simultaneous monodisciplinary workshops. Journal of Housing for the Elderly, 28(4), 329-356.

van Hoof, J., Wetzels, M. H., Dooremalen, A. M. C., Wouters, E. J. M., Nieboer, M. E., Sponselee, A. A. M., et al. (2014c). Technological and architectural solutions for Dutch nursing homes: Results of a multidisciplinary mind mapping session with professional stakeholders. Technology in Society, 36, 1-12.

van Hoof, J., Wetzels, M. H., Dooremalen, A. M. C., Overdiep, R. A., Nieboer, M. E., Eyck, A. M. E., van Gorkom, P. J. L. M., Zwerts-Verhelst, E. L. M., Aarts, S., Vissers-Luijcks, C., van der Voort, C. S., Moonen, M. J. G. A., van de Vrande, H. A., van Dijck-Heinen, C. J. M. L., \& Wouters, E. J. M. (2015a). Exploring innovative solutions for quality of life and care of bedridden nursing home residents through co-design sessions. Journal of Aging Research, 2015, Article ID 185054.

van Hoof, J., Zwerts-Verhelst, E. L. M., Nieboer, M. E., \& Wouters, E. J. M. (2015b). Innovations in multidisciplinary education in healthcare and technology. Perspectives on Medical Education, 4(3), 146-148. 
van Hoof, J., Zwamborn, M., Metz, S., \& Bosems, W. (2015c). Senioren in de klas als verrijking van het onderwijs. Onderwijs en Gezondheidszorg, 40(2), 22-25. (in Dutch).

Ventura-Merkel, C., \& Lidoff, L. (1983). Program innovation in aging: Vol. 8, Community planning for intergenerational programming. Washington, DC: National Council on Aging.

Wilson, B. (1992). Memory therapy in practice. In Clinical management of memory problems (pp. 120-153). Boston: Springer.

Wright, S. C., Aron, A., McLaughlin-Volpe, T., \& Ropp, S. A. (1997). The extended contact effect: Knowledge of cross-group friendships and prejudice. Journal of Personality and Social Psychology, 73, 73-90.

Open Access This chapter is licensed under the terms of the Creative Commons Attribution 4.0 International License (http://creativecommons.org/licenses/by/4.0/), which permits use, sharing, adaptation, distribution and reproduction in any medium or format, as long as you give appropriate credit to the original author(s) and the source, provide a link to the Creative Commons license and indicate if changes were made.

The images or other third party material in this chapter are included in the chapter's Creative Commons license, unless indicated otherwise in a credit line to the material. If material is not included in the chapter's Creative Commons license and your intended use is not permitted by statutory regulation or exceeds the permitted use, you will need to obtain permission directly from the copyright holder. 